\title{
Empirical verification of self-rated positive health (somatic dimension) in women with professional competence in the field of health education
}

\author{
Dobosz D. ${ }^{\mathrm{ABCDE}}$ \\ Niepubliczny Zakład Opieki Zdrowotnej Ośrodek Rehabilitacji Marek Grodzki, Tychy, Poland
}

Authors' Contribution: A - Study design; B - Data collection; C - Statistical analysis; D - Manuscript preparation; $\mathrm{E}-$ Funds collection.

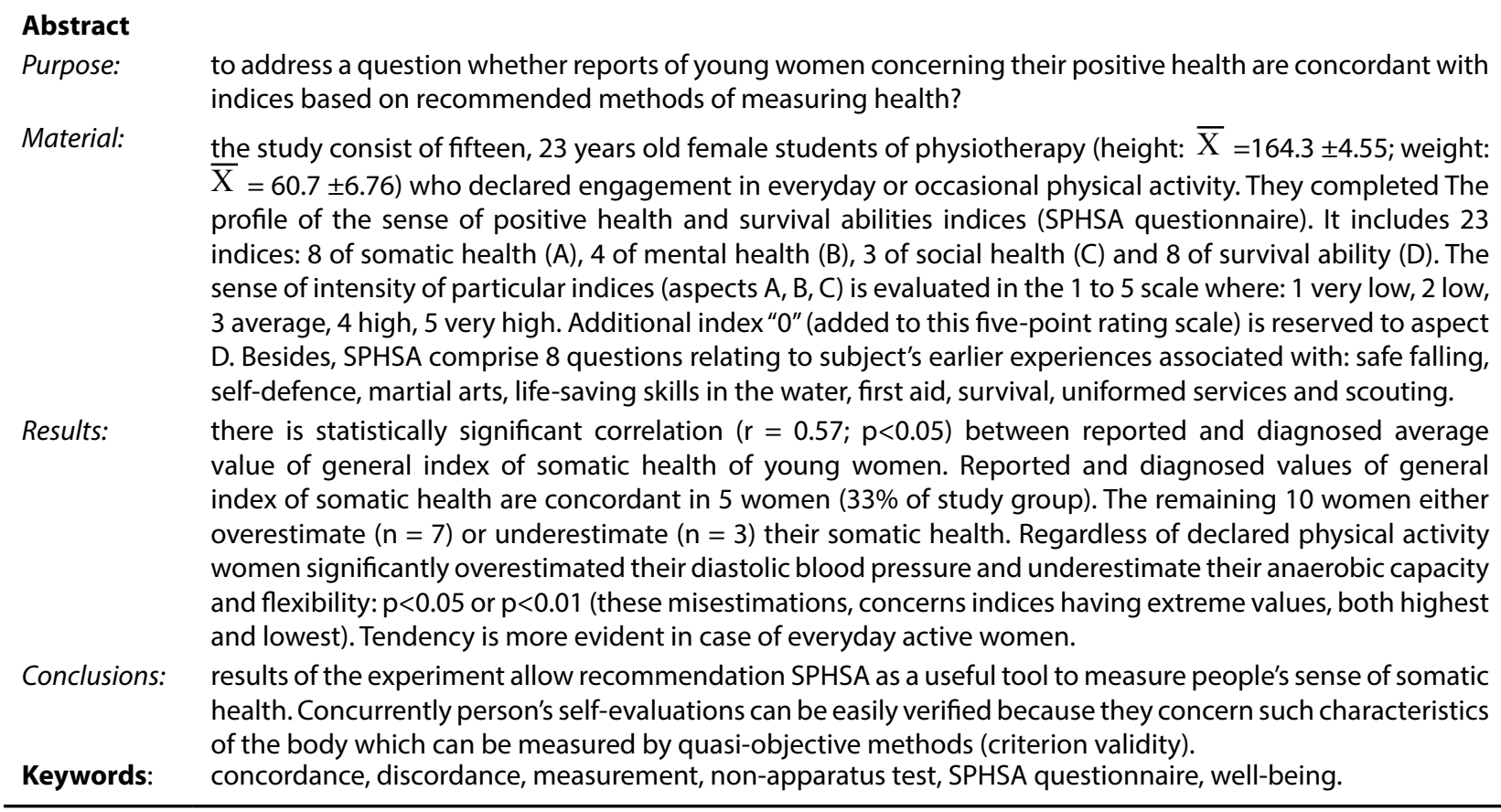

\section{Introduction}

According to WHO „Health is a state of complete physical, mental and social well-being and not merely the absence of disease or infirmity [1]. Experts distinguish two dimensions of well-being: subjective and objective [2] what means that evaluation of people's health can be based on either subjective (based on self-reports) or objective methods (e.g. laboratory tests).

People's self-reports may concern various types of information relating to any health dimension. It is reflected by number of available health questionnaires [3]. They can be divided into general health [4] and condition-specific measures [5]. Among the former measures self-rated health (SRH) is one of the most popular. It's considered to be valid, reliable and cost-effective [6]. Besides, SRH as summary measure incorporates amount information about people's health which could be difficult to obtain even by larger set of more objective measures [7, 8]. Nonetheless, SRH is prone to bias related to e.g. cultural factors [9], age [10]. It's important, because effectiveness of programs and polices targeted at improving people's health which are based only on self-reports depend on their accuracy [11]. Moreover people's misestimations concerning their health may lead to overuse or underuse health services

\section{$[12,13]$}

Results of recent longitudinal study revealed that predictive validity (related to mortality) of SRH increases. Authors suggest that it may stem from availability of larger amount of high quality information which people can include in their self-assessment. It's noteworthy that relation between SRH and mortality is stronger if information are got from physician than other sources e.g. relatives, media [14]. It's not surprising since physicians and other health care providers (physiotherapist, nurses etc.) share with people not only deepened knowledge (often available in the internet) about human health but also about skills required to proper use of it. Moreover those among them who practice healthy behaviours by themselves extend their influence on society by serving as health role models $[15,16]$.

There may be two types of relationship between reported and diagnosed (on the basis of recommended methods) values of indices of positive health: concordance and discordance. Concordance can be complete either in the absolute sense or in assumed boundaries of similarity considered (according to accepted criteria) to be high or close to complete. Discordance encompass overestimation or underestimation or combination both of them if there is more than one index of positive health. 
Concordance between reported and diagnosed values of indices of positive health doesn't give grounds to ascertain that particular person is highly competent in the field of health education. However result can be used as the most general index of accuracy of such competencies measured with knowledge tests (criterion validity).

The aim of this study is to address a question whether reports of young women concerning their positive health are concordant with indices based on recommended methods of measuring health?

\section{Material and methods}

Participants.

The study consist of fifteen, 23 years old female students of physiotherapy (height: $\bar{X}=164.3 \pm 4.55$; weight: $\bar{X}=60.7 \pm 6.76$ ) who declared engagement in everyday or occasional physical activity.

Research design.

They completed the profile of the sense of positive health and survival abilities indices (SPHSAquestionnaire) [12]. It includes 23 indices: 8 of somatic health (A), 4 of mental health (B), 3 of social health (C) and 8 of survival ability (D). The sense of intensity of particular indices (aspects A, B, C) is evaluated in the 1 to 5 scale where: 1 very low, 2 low, 3 average, 4 high, 5 very high. Additional index " 0 " (added to this five-point rating scale) is reserved to aspect D. Besides, SPHSA comprise 8 questions relating to subject's earlier experiences associated with: safe falling, self-defence, martial arts, life-saving skills in the water, first aid, survival, uniformed services and scouting.

Women's reports concerning somatic health (with the exception of aerobic capacity) were empirically verified. Women's height and weight (for BMI calculation) were measured along with resting heart rate and blood pressure. Also, women performed 5 recommended motoric tests for measuring: anaerobic capacity (30-sec Burpee test), flexibility (non-apparatus flexibility test), muscle strength (standing long jump, 10-sec press-ups, 30-sec sit ups) [17].

\section{Statistical Analysis.}

Statistical analysis (made with the help of Excel) involved calculating correlation coefficient between values and tests for significance of the differences between means (reported versus diagnosed values of indices).

\section{Results}

There is statistically significant correlation $(\mathrm{r}=0.57$; $\mathrm{p}<0.05$ ) between reported and diagnosed average value of general index of somatic health of young women (Fig. 1).

Reported and diagnosed values of general index of somatic health are concordant in 5 women who constitute $33 \%$ of study group. The remaining 10 women either overestimate $(n=7)$ or underestimate $(n=3)$ their somatic health however this discordances are not very large therefore difference between declared and diagnosed value of general index of somatic health, in the sense of the average result, is not statistically significant (Fig. 2).

Regardless of declared physical activity women significantly overestimated their diastolic blood pressure and underestimate their anaerobic capacity and flexibility: $\mathrm{p}<0.05$ or $\mathrm{p}<0.01$. It's conspicuous, that these misestimations, concerns indices having extreme values (both highest and lowest). Tendency is more evident in case of everyday active women (Fig. 3, 4).

Concordance between reported and diagnosed average value of general index of somatic health of 5 women doesn't mean that they assessed accurately intensity of every detailed indices of somatic health. Level of muscle strength was accurately assessed by all women but only four of them (exception: woman with code K3) assessed accurately intensity of their resting heart rate. Two women hardly assessed accurately their BMI (code K1 and K2). All women overestimate level of their blood pressure (both systolic and diastolic) and underestimate their anaerobic capacity and flexibility (Fig. 5 to 9)

Reported and diagnosed value of general index of somatic health of woman with code K13 differs slightly ( $\bar{X}_{r}=2.71 ; \bar{X}_{d}=2.86$ resp.). However her misestimations concerning detailed indices of somatic health don't

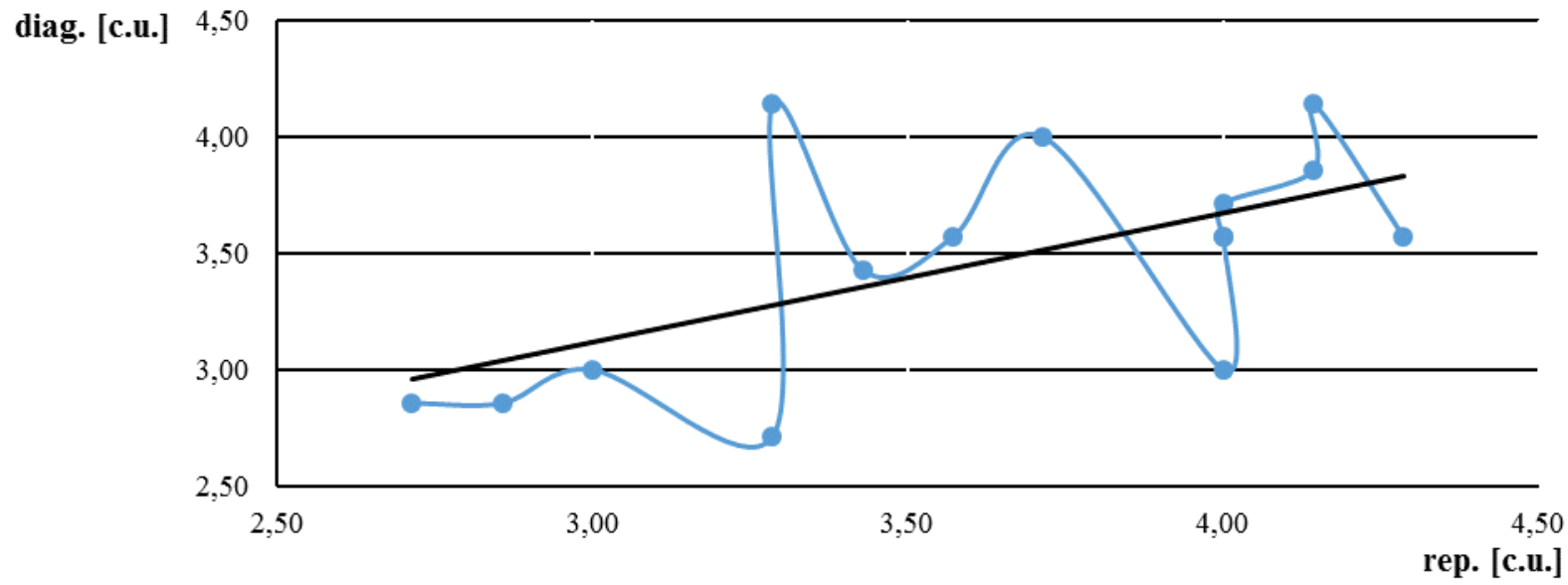

Fig. 1. The relationship between reported (rep.) and diagnosed (diag.) average value (conventional units; c.u.) of general measure of somatic health of 15 young women (relatively to regression line): $r=0.57(p<0.05)$. 


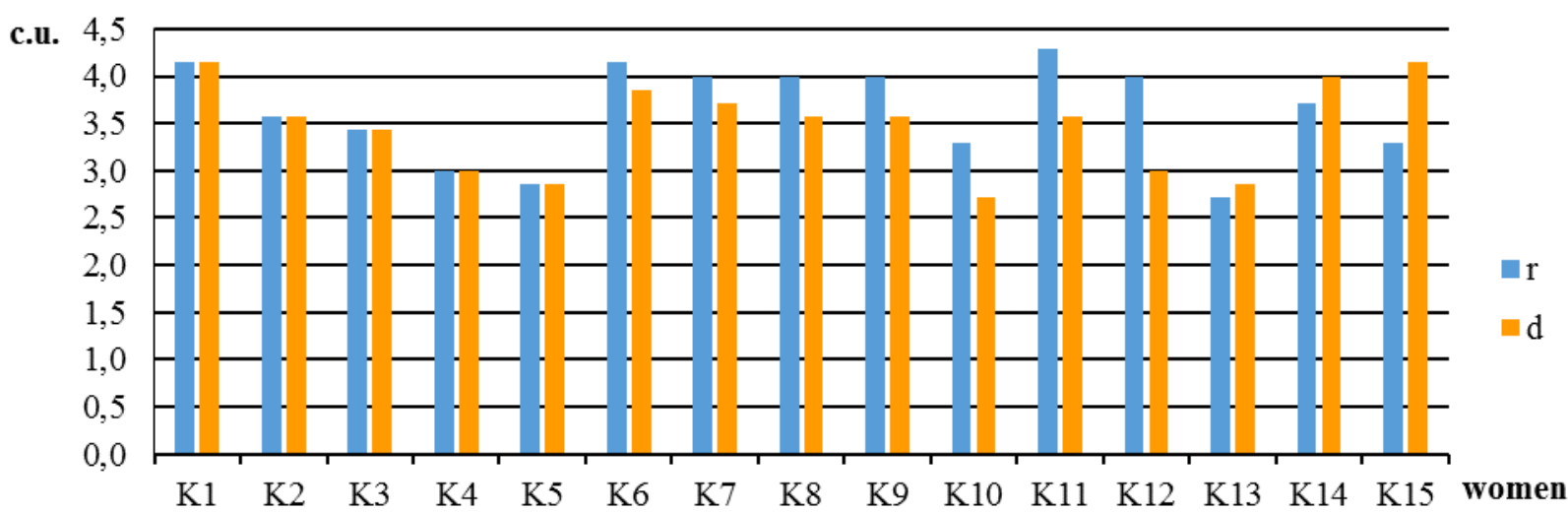

Fig. 2. Reported ( $r$ ) and diagnosed (d) values (conventional units; c.u.) of general index of somatic health of young women $(n=15)$. Results subsets: K1 to K5 concordance; K6 to K12 overestimation; K13 to K15 underestimation.

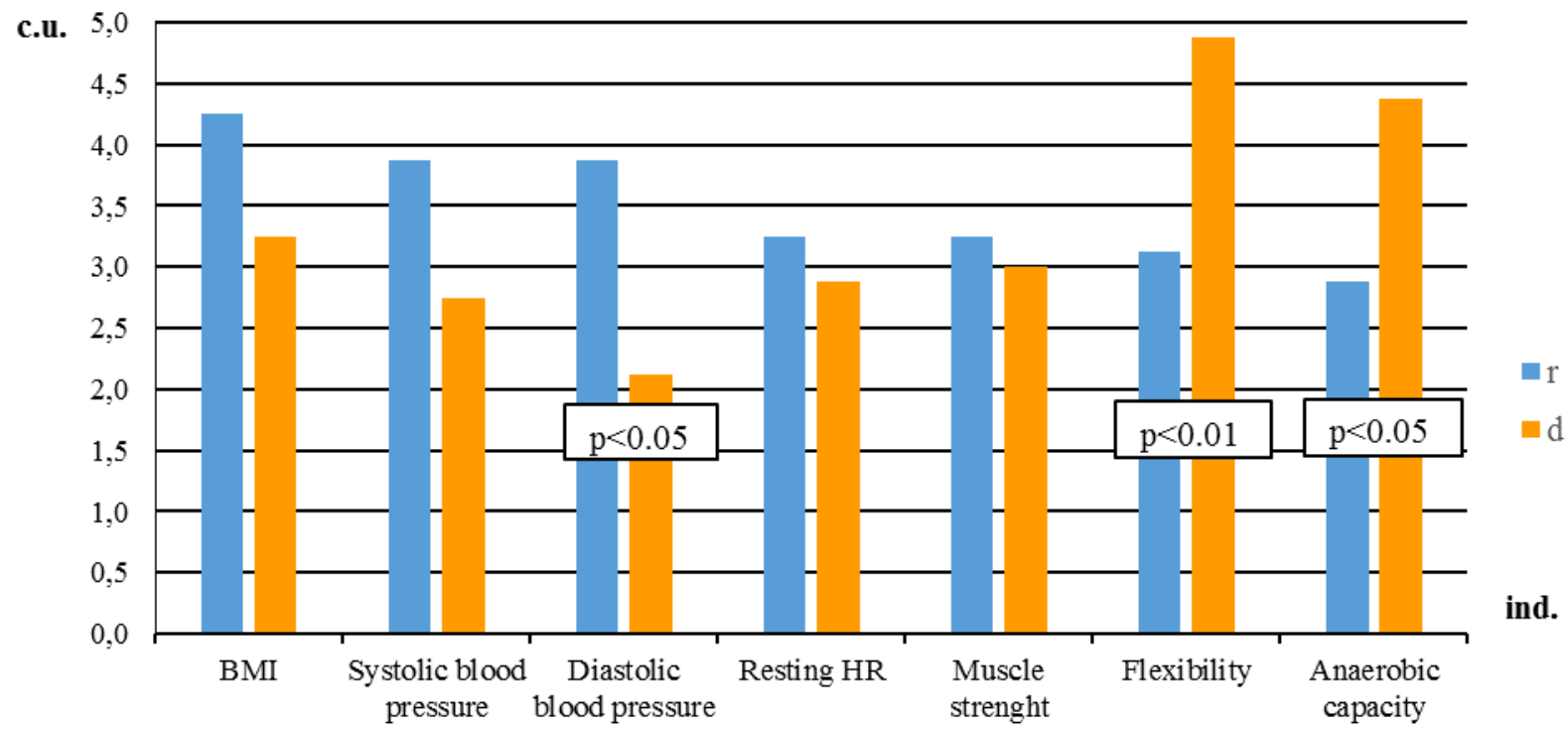

Fig. 3. Reported ( $r$ ) and diagnosed (d) values (conventional units; c.u.) of detailed indices (ind.) of somatic health of women declaring occasional physical activity $(n=8)$. Ordinal variable: reported intensity of particular indices of somatic health (from the highest to the lowest value).

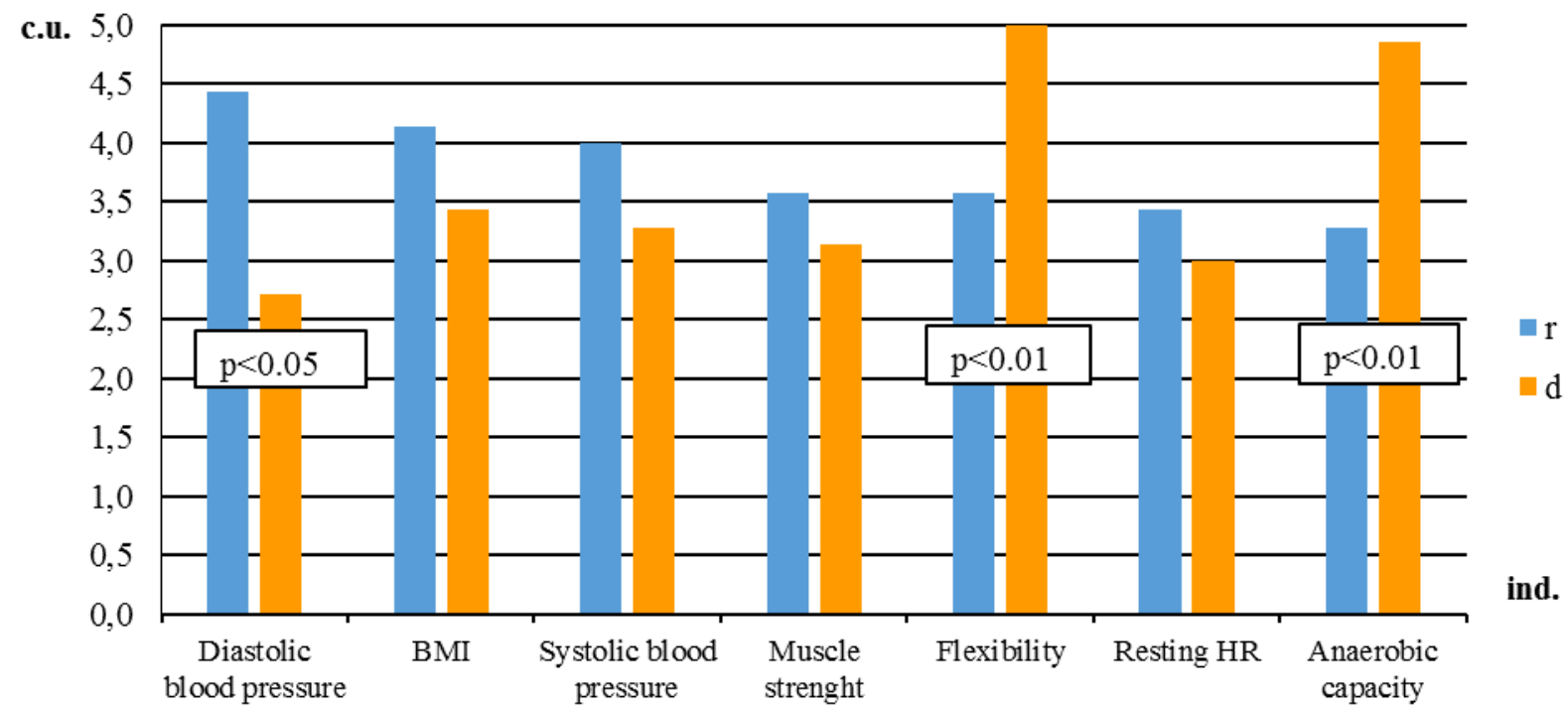

Fig. 4. Reported ( $r$ ) and diagnosed (d) values (conventional units; c.u.) of detailed indices (ind.) of somatic health of women declaring everyday physical activity $(n=7)$. Ordinal variable: reported intensity of particular indices of somatic health (from the highest to the lowest value). 


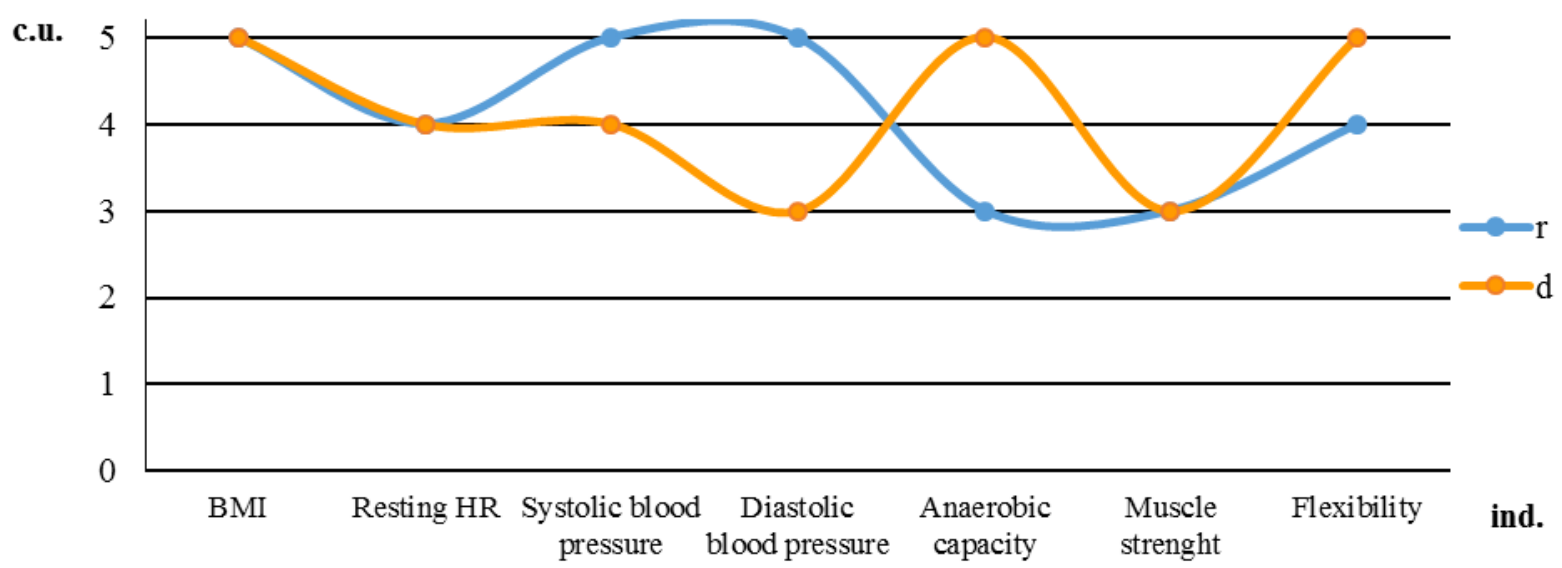

Fig. 5. Profile of reported ( $r$ ) and diagnosed (d) values (conventional units; c.u.) of detailed indices (ind.) of somatic health of young woman (code K1)

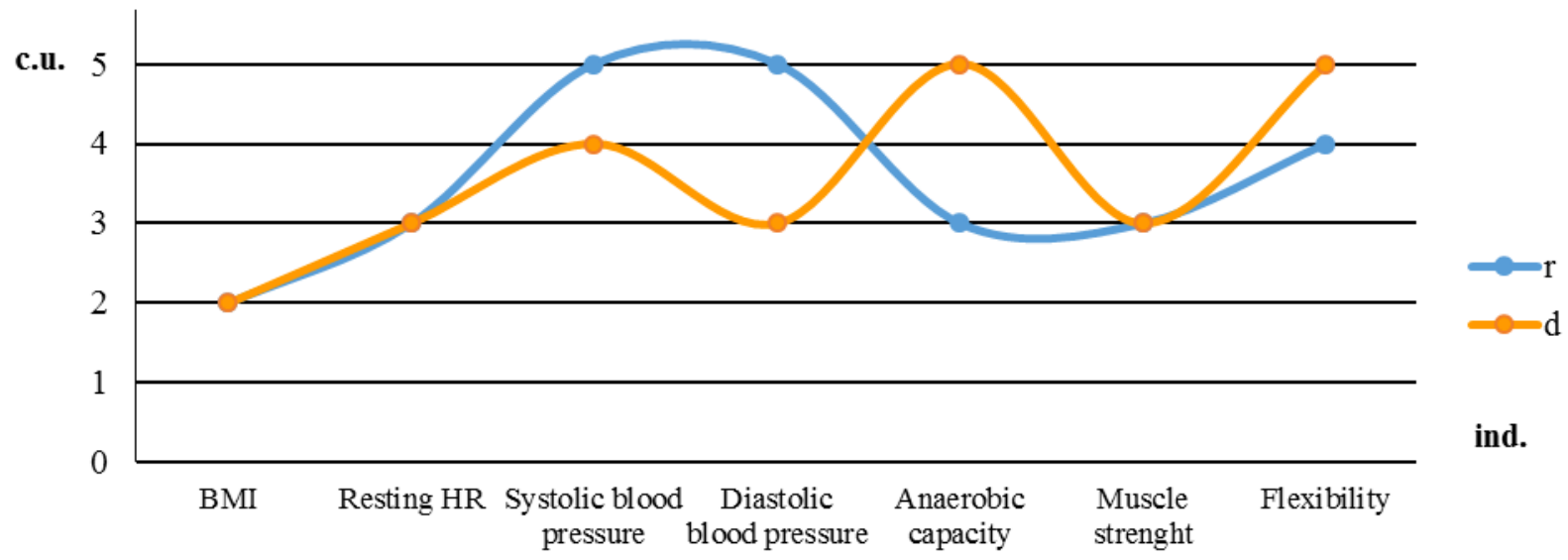

Fig. 6. Profile of reported ( $r$ ) and diagnosed (d) values (conventional units; c.u.) of detailed indices (ind.) of somatic health of young woman (code K2).

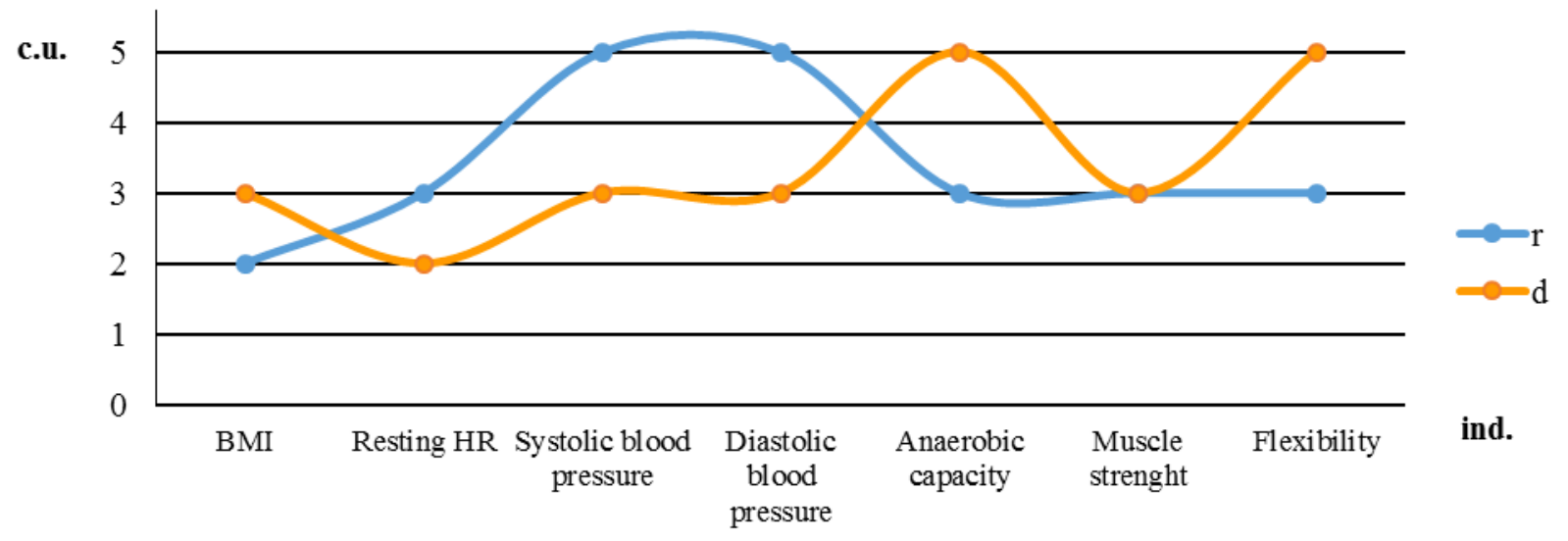

Fig. 7. Profile of reported ( $r$ ) and diagnosed (d) values (conventional units; c.u.) of detailed indices (ind.) of somatic health of young woman (code K3). 


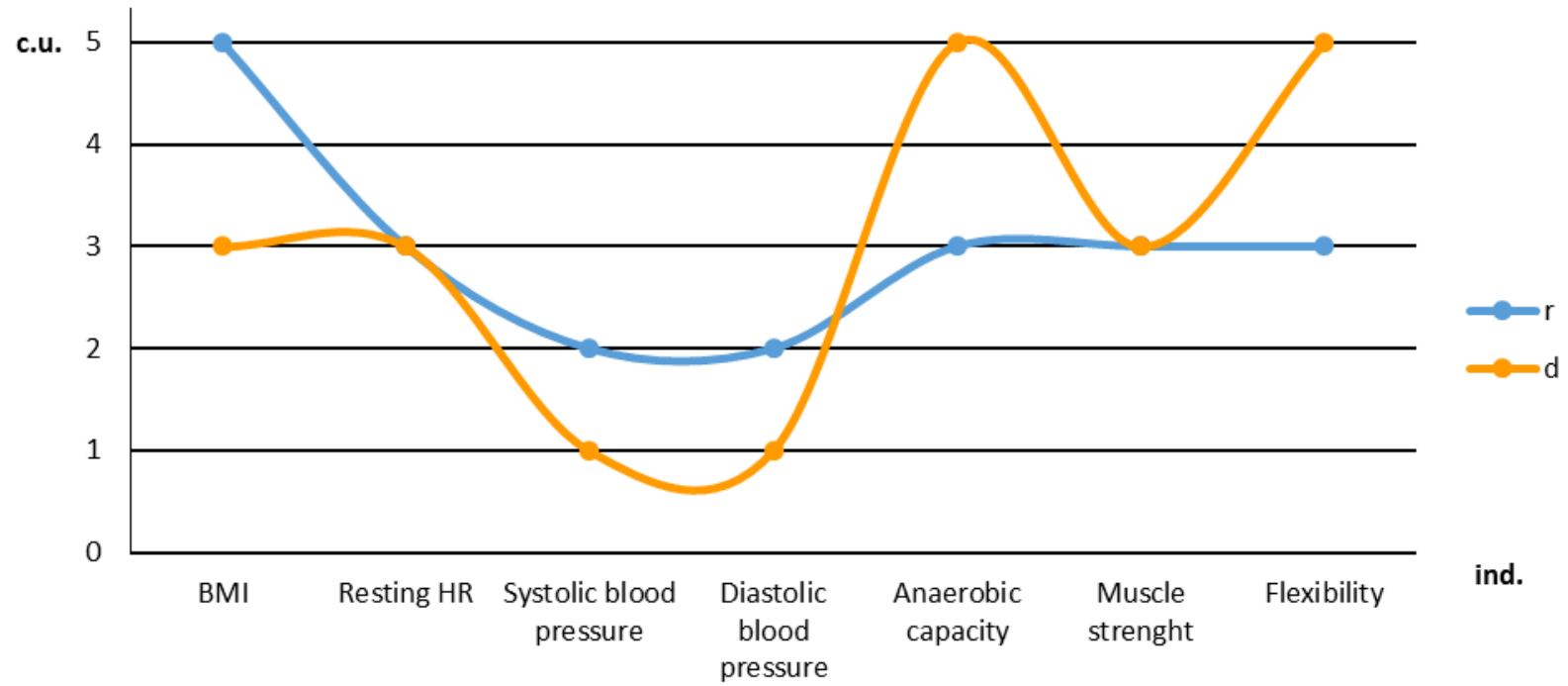

Fig. 8. Profile of reported ( $r$ ) and diagnosed (d) values (conventional units; c.u.) of detailed indices (ind.) of somatic health of young woman (code K4).

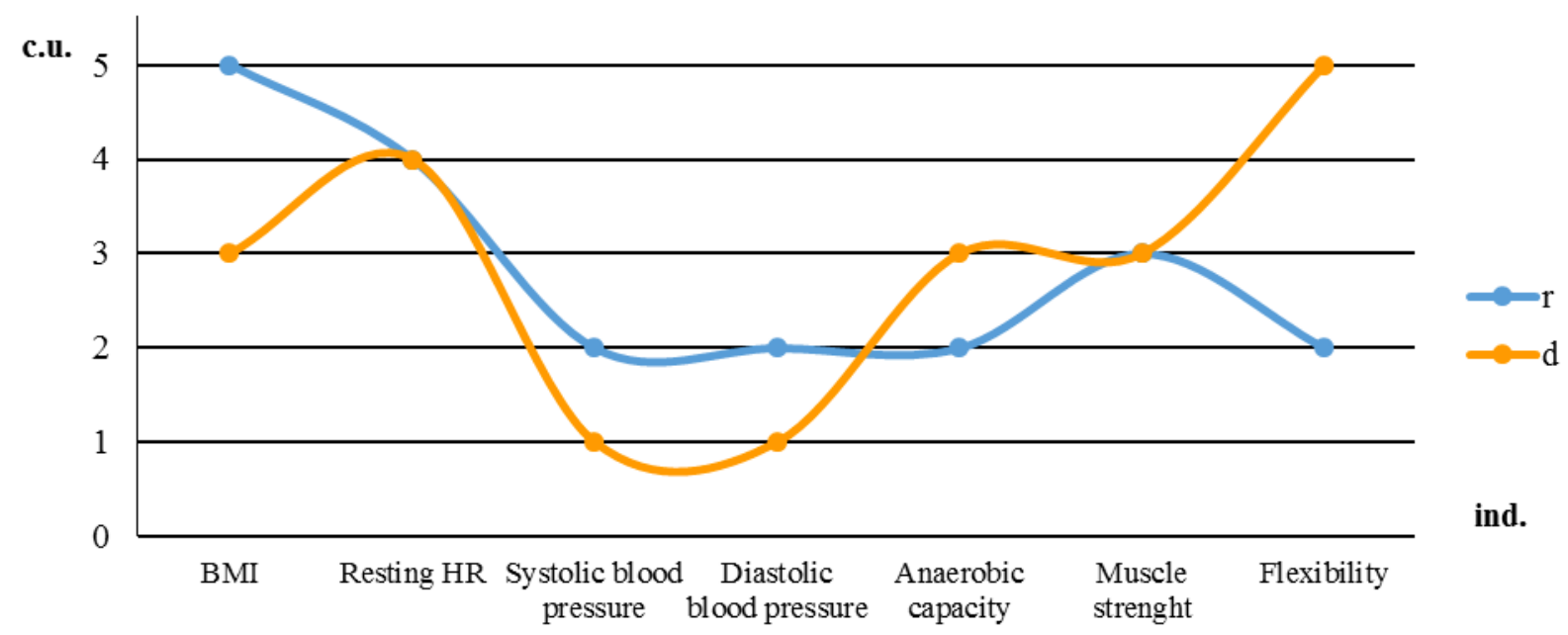

Fig. 9. Profile of reported ( $r$ ) and diagnosed (d) values (conventional units; c.u.) of detailed indices (ind.) of somatic health of young woman (code K5).

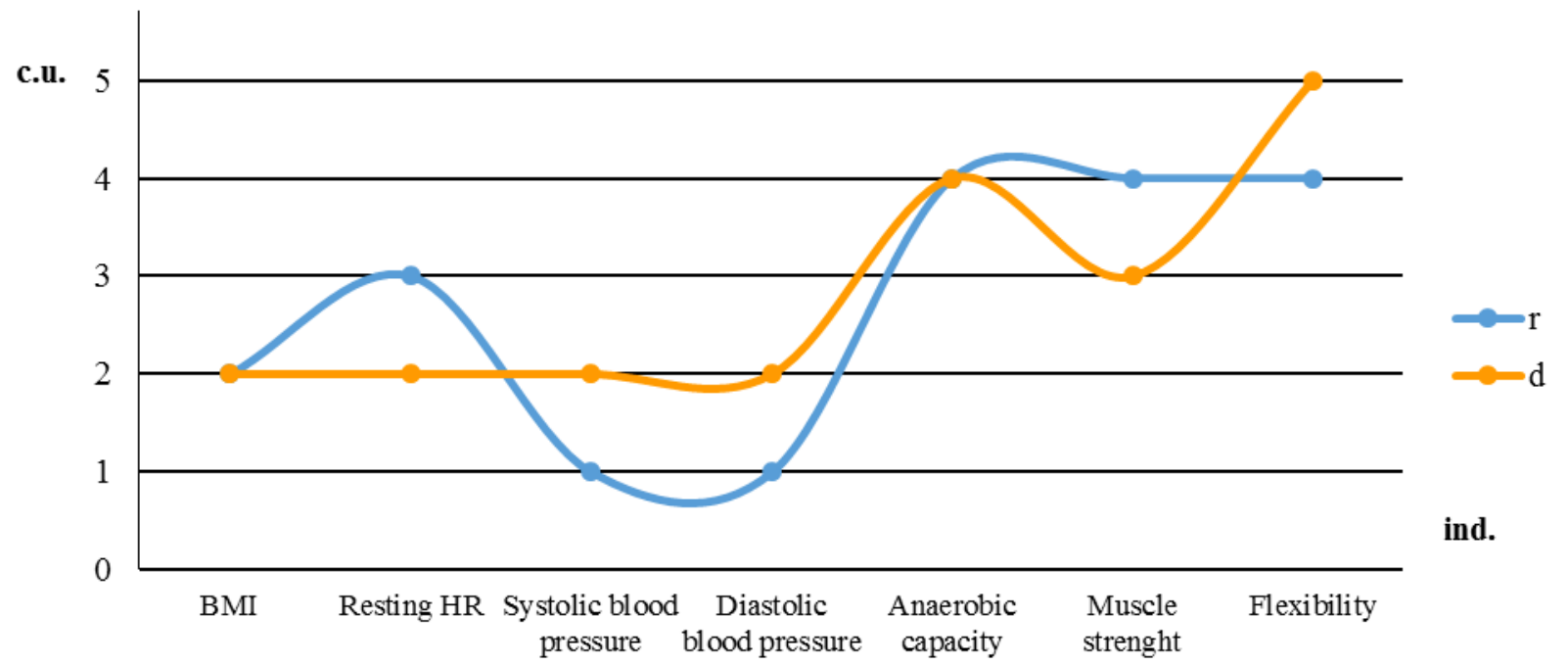

Fig. 10. Profile of reported ( $r$ ) and diagnosed (d) values (conventional units; c.u.) of detailed indices (ind.) of somatic health of young woman (code K13). 


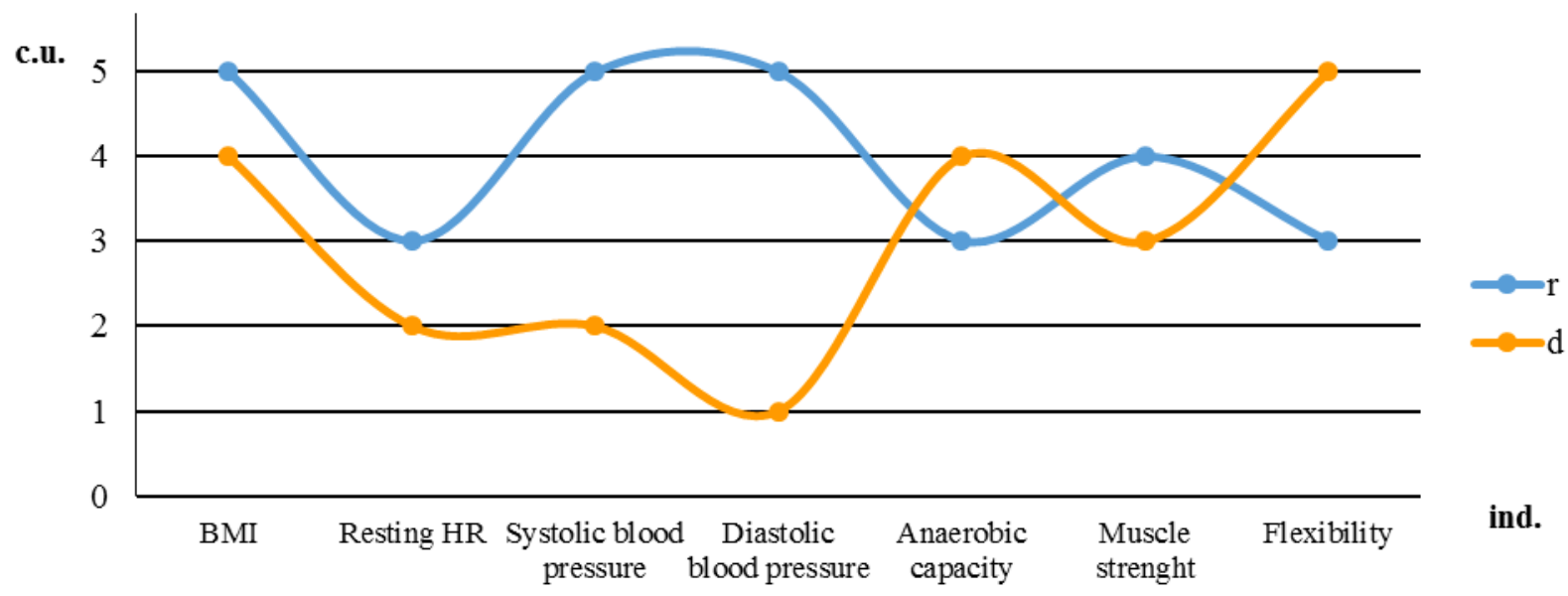

Fig. 11. Profile of reported ( $r$ ) and diagnosed (d) values (conventional units; c.u.) of detailed indices (ind.) of somatic health of young woman (code K12).

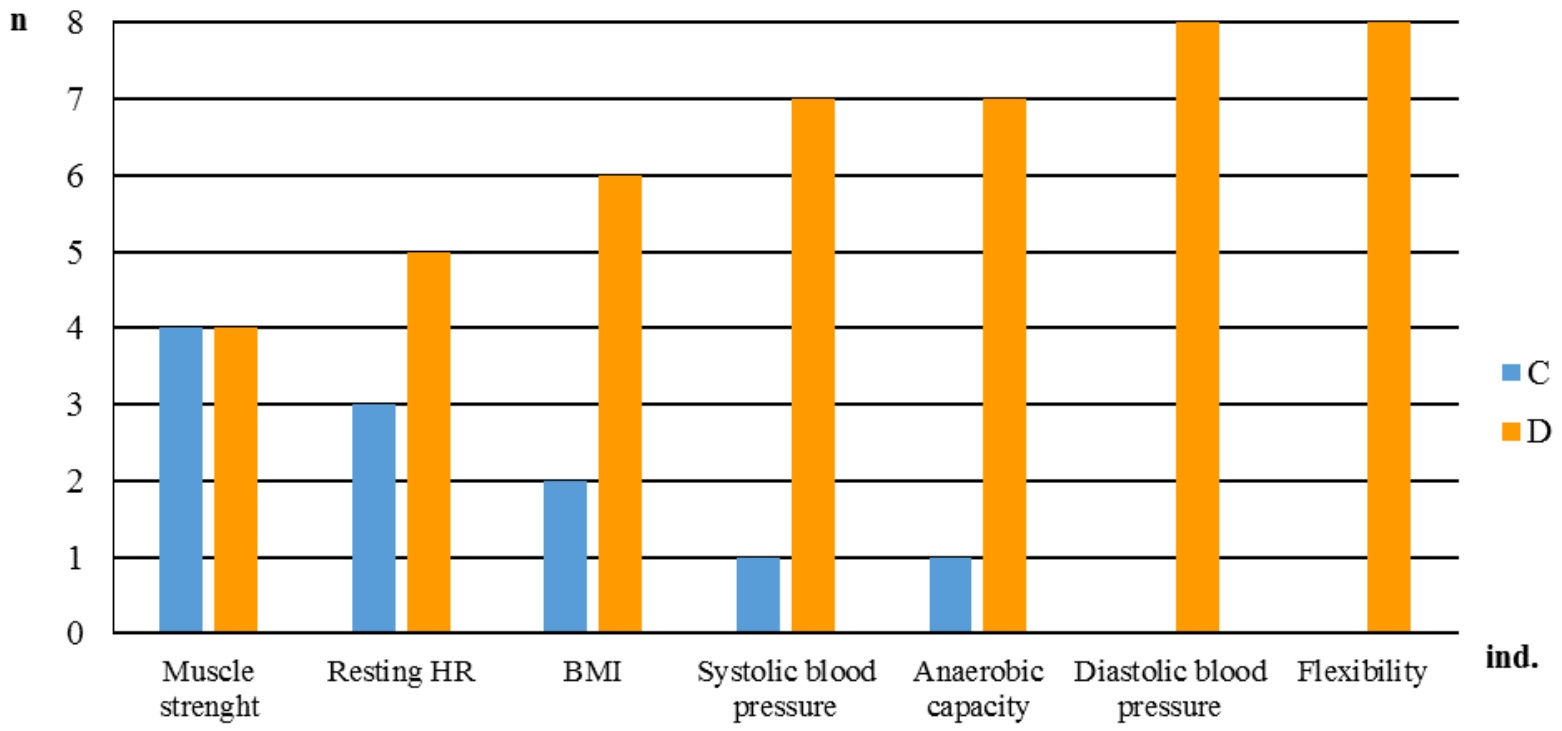

Fig. 12. Number ( $n$ ) of concordances (C) and discordances (D) between reported and diagnosed values of detailed indices (ind.) of somatic health of young women declaring occasional physical activity $(n=8)$. Ordinal variable: amount of concordances (from the highest to the lowest value).

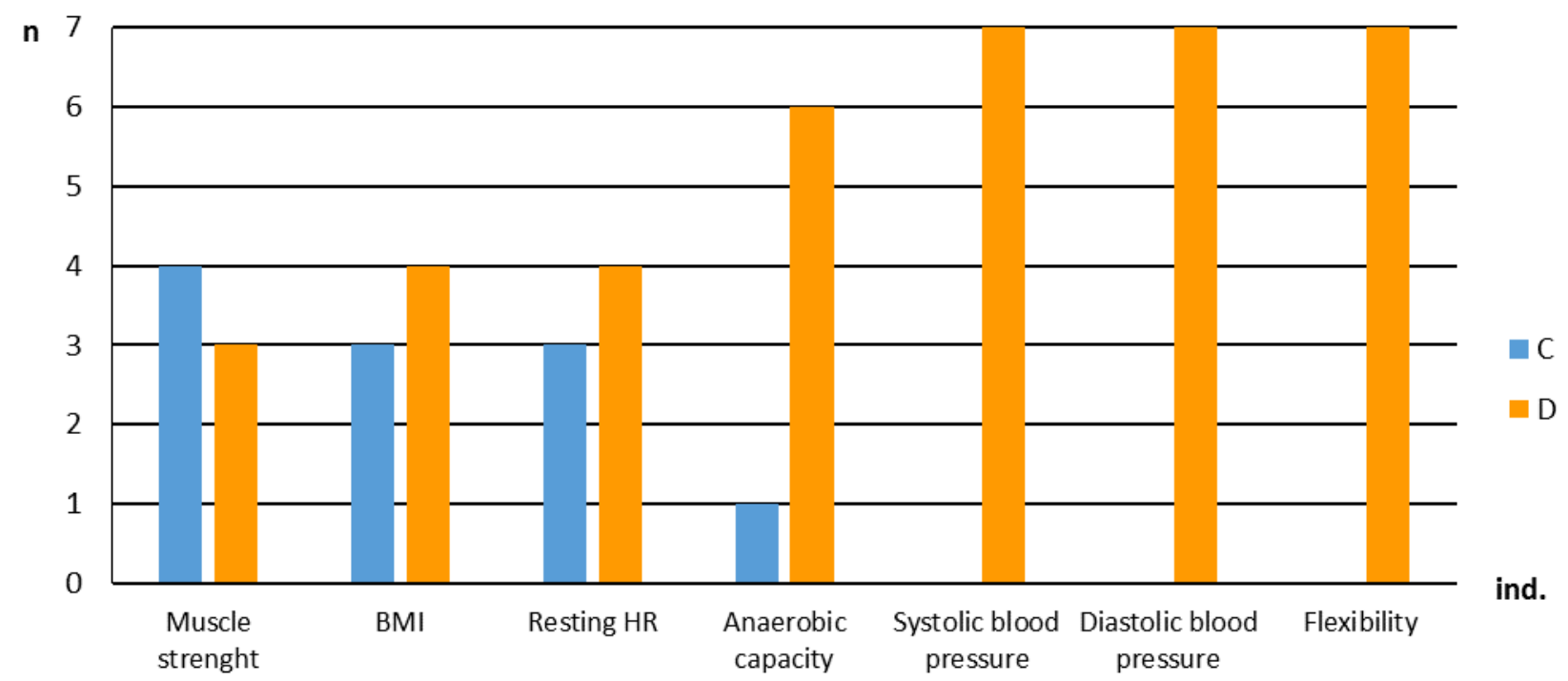

Fig. 13. Number ( $n$ ) of concordances (C) and discordances (D) between reported and diagnosed values of detailed indices (ind.) of somatic health of young women declaring everyday physical activity $(n=7)$. Ordinal variable: number of concordances (from the highest to the lowest value). 
exceed more than one conventional unit in contrast to women with codes K1 to K5. She assessed accurately intensity of two detailed indices of somatic health: BMI and anaerobic capacity (Fig. 10).

Reported and diagnosed value of general index of somatic health of woman with code K12 differs more in comparison to woman with code K13 (1 conventional unit). She overestimated 5 detailed indices of her somatic health: BMI, resting heart rate and muscle strength 1 conventional unit; systolic and diastolic blood pressure 3 and 4 conventional units, respectively. She underestimated her anaerobic capacity and flexibility: 1 and 2 conventional units respectively. (Fig.11).

On the whole, concordance between reported and diagnosed value of detailed indices of somatic health among women (regardless of declared physical activity) the most often occurred with regard to muscle strength. In case of diastolic blood pressure and flexibility there were only discordances (Fig.12, 13). In both groups of women discordances between reported and diagnosed values in 5 out of 7 detailed indices of somatic health were primarily a result of overestimation. All young women underestimate their anaerobic capacity and flexibility (Fig. 14, 15).

\section{Discussion}

There is high convergence of reported and diagnosed values of general index of somatic health of women. Taking coefficient of determination $\left(\mathrm{r}^{2}=0.33\right)$ into consideration it is justified to state that $33 \%$ of power of this relationship can be ascribed to concordance between reported and diagnosed value of general index of somatic health in 5 women. Similar value of coefficient of determination and

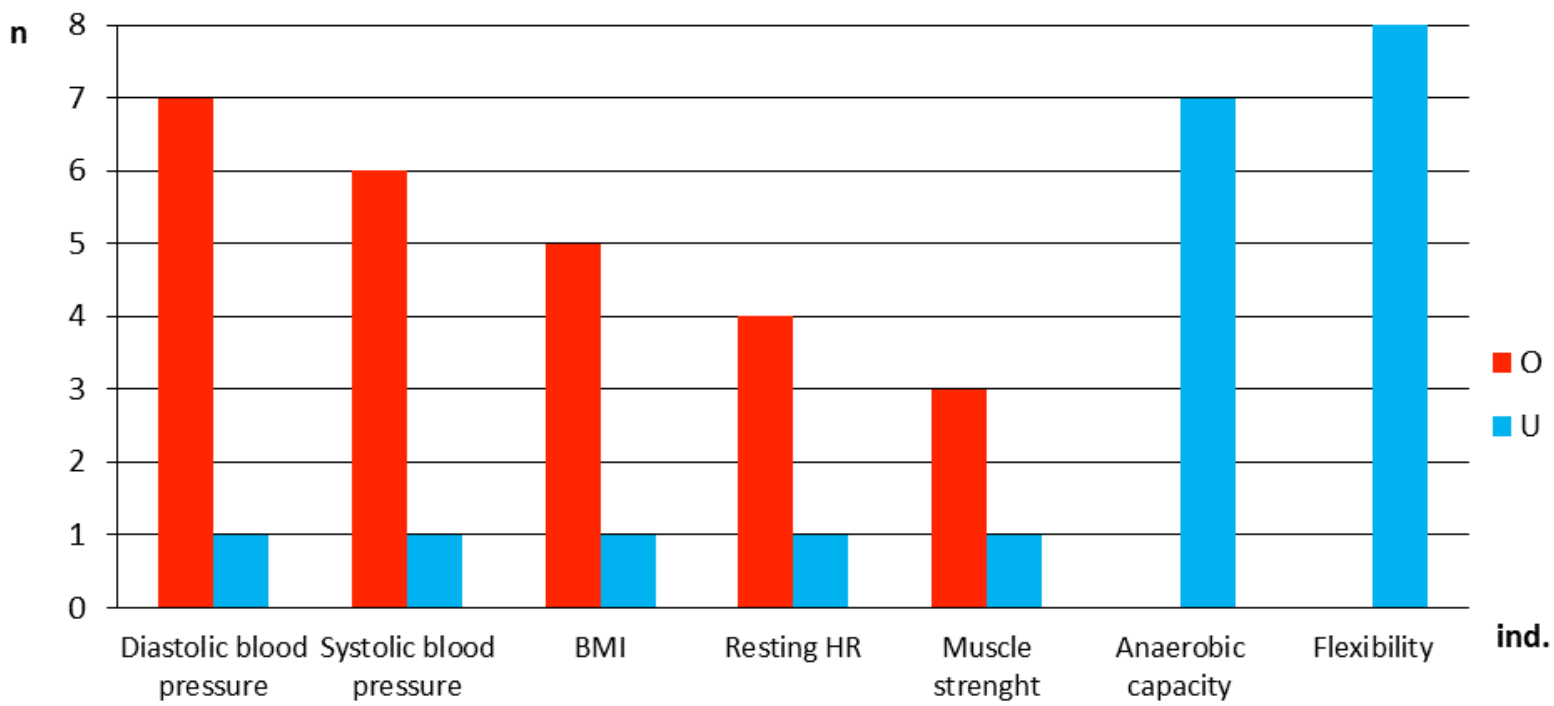

Fig. 14. Number $(n)$ of overestimations $(O)$ and underestimations $(U)$ among young women declaring occasional physical activity $(n=8)$ concerning detailed indices (ind.) of somatic health. Ordinal variable: amount of overestimations (from the highest to the lowest value).

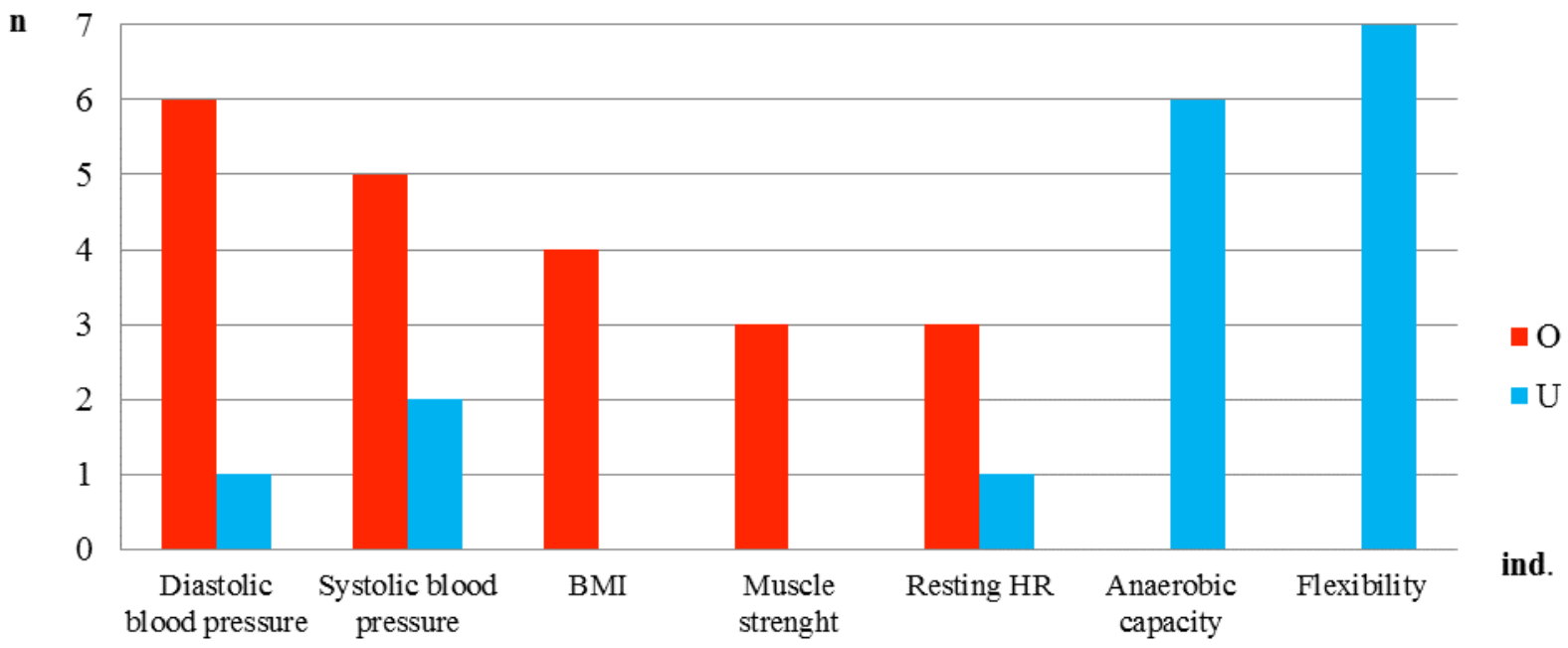

Fig 15. Number $(n)$ of overestimations $(O)$ and underestimations $(U)$ among young women declaring everyday physical activity $(n=7)$ concerning detailed indices (ind.) of somatic health. Ordinal variable: amount of overestimations (from the highest to the lowest value). 
percent of proportion confirms that.

There are no significant differences between reported average value of general index of somatic health of female students of physiotherapy examined in this research and female students of the faculty of tourism and recreation [18] and female students of physiotherapy from earlier studies [12]. It doesn't matter whether comparative analysis pertains to women declaring occasional $(\overline{\mathrm{X}}=$ $3.500 ; \quad \bar{X}=3.195 ; \quad \bar{X}=3.263$ resp.) or everyday ( $\bar{X}$ $=3.776 ; \bar{X}=3.552 ; \bar{X}=3.523$ resp.) physical activity.

Both the latter evoked study and my research confirmed that women who declare everyday physical activity has tendency to report higher values of detailed indices of somatic health in comparison with women who declare occasional physical activity. In both studies regardless of declared physical activity women rated the highest their systolic and diastolic blood pressure and BMI. Obversely they rated the lowest their flexibility, aerobic and anaerobic capacity. Empirical verification proved that the most discordances between reported and diagnosed values occurred in relation to this detailed indices of somatic health (excluding BMI and aerobic capacity).

It's obvious in case of anaerobic capacity and flexibility that women declaring occasional physical activity underestimated them because this women generally has limited amount of opportunities to verify their perceptions of their motoric abilities. Whereas women declaring everyday physical activity did the same because their physical activity is restricted to endurance exercises which don't involve movements with extreme range of motion (fitness, running, cycling). The fact that among women declaring everyday physical activity only one (code K13) who declared practicing weight training accurately assessed her anaerobic capacity is empirical evidence of that conclusion. This is also a reason (low variety of types of physical activity) why the extent of differences between reported and diagnosed values of anaerobic capacity and flexibility of both groups of women are similar (don't exceed 2 conventional units; exception woman with code K5 declaring occasional physical activity 3 conventional units). Women overestimated their systolic and diastolic blood pressure probably because variations of both of them are mainly sensible when concern pathological conditions (hypertension, hypotension) in contrast to previous two motor abilities which perception can be built on self-observation own activity during a day (e.g. running to the bus stop, adopting unusual body position during work).

Results of the experiment allow recommendation SPHSA as a useful tool to measure people's sense of somatic health. Since one report sense of intensity of predetermined and commonly accepted indices of somatic health (BMI, resting heart rate, systolic and diastolic blood pressure etc.) so possibility that his/her declarations will be based on premises not associated with health is minimized (construct validity). Concurrently person's self-evaluations can be easily verified because they concern such characteristics of the body which can be measured by quasi-objective methods (criterion validity).

At least three issues remain to address. Is there concordance between reported and diagnosed value of indices of other health dimensions (mental, social) and survival abilities in female students of physiotherapy? Do female and male students of physiotherapy differ in assessment accuracy? Is there concordance between reported and diagnosed values of indices of health and survival abilities in students (men and women) of other faculties related to health (medical, nursing, pharmaceutical)?

There are grounds to claim that after four years of education female students of physiotherapy has high theoretical competences concerning health education so results of empirical investigation proves it in the sense of general index (SPHSA). Regular self-observation of one's own body should be distinctive feature of every graduate of faculty related to health. Although SPHSA questionnaire has been applied in few previous studies [ 12 , 18-20], it's worth noting, that this is a first time in which declared values of somatic health indices were empirically verified. Recommended methods for measurement of somatic health and survival abilities in the framework of the SPHSA questionnaire [17] should be considered as propositions. It especially relates to survival ability e.g. body balance assessment may be based on both more (The Flamingo balance test, Romberg test, Tinetti balance test etc.) and less popular tests (such as these designed to evaluation sambo and judo athletes [21-23]). Similar reasoning also refers to indices of mental and social health. In this regard method self-assessment applied in few studies incl. aggressiveness of judo athletes [24] is worth noting. There is one main prerequisite concerning tests selection: they have to be adjusted to established framework of the SPHSA questionnaire methodology: appropriate decomposition of their values $[12,17]$.

\section{Conclusions}

Results of the experiment allow recommendation SPHSA as a useful tool to measure people's sense of somatic health. Concurrently person's self-evaluations can be easily verified because they concern such characteristics of the body which can be measured by quasi-objective methods (criterion validity).

\section{Conflict of interest}

The author declare no conflict of interest. 


\section{References}

1. Constitution of The World Health Organization. New York: World Bank; 1946.

2. Measurement of and target-setting for well-being: an initiative by the WHO. Regional Office for Europe; June; 2012.

3. McDowell I. Measuring health: a guide to rating scales and questionnaires. 3rd ed. New York (NY): Oxford University Press; 2006. https://doi.org/10.1093/acprof:oso/9780195165678.001.0001

4. Ware JE Jr, Sherbourne CD. The MOS 36-item shortform health survey (SF-36). I. Conceptual framework and item selection. Med Care, 1992; 30: 473- 83. https://doi.org/10.1097/00005650-199206000-00002

5. Bjordal K, de Graeff A, Fayers P., Hammerlid E, van Pottelsberghe C, Curran D, et al. A 12 country field study of the EORTC QLQ-C30 (version 3.0) and the head and neck cancer specific module (EORTC QLQ-H\&N35) in head and neck patients. European Journal of Cancer, 2000;36:1796-807 https://doi.org/10.1016/S0959-8049(00)00186-6

6. Kaplan G, Baron-Epel O. What lies behind the subjective evaluation of health status? Soc Sci Med. 2003; 56: 1669- 76. https://doi.org/10.1016/S0277-9536(02)00179-X

7. Jylhä M, Volpato S, Guralnik JM. Self-rated health showed a graded association with frequently used biomarkers in a large population sample. J Clin Epidemiol. 2006; 59: 465- 71. https://doi.org/10.1016/j.jclinepi.2005.12.004

8. Heidrich J. Self-Rated Health and its Relation to AllCause and Cardiovascular Mortality in Southern Germany. Results from the MONICA Augsburg Cohort Study 1984-1995. Annals of Epidemiology, 2002;12:338-45. https://doi.org/10.1016/S1047-2797(01)00300-3

9. Baron-Epel O, Kaplan G, Haviv-Messika A, Tarabeia J, Green MS, Nitzan Kaluski D. Self-reported health as a cultural health determinant in Arab and Jewish Israelis. Social Science \& Medicine, 2005;61:1256-66. https://doi.org/10.1016/j.socscimed.2005.01.022

10.Leinonen R, Heikkinen E, Jylhä M. Predictors of decline in self-assessments of health among older people--a 5-year longitudinal study. Soc Sci Med. 2001; 52: 1329- 41. https://doi.org/10.1016/S0277-9536(00)00249-5

11. Sherry B, Jefferds ME, Grummer-Strawn LM. Accuracy of adolescent self-report of height and weight in assessing overweight status: a literature review. Arch Pediatr Adolesc Med. 2007; 161: 1154- 61. https://doi.org/10.1001/archpedi.161.12.1154

12.Kalina RM. The profile of Sense of Positive Health and Survival Abilities indices (subjective assessment) as a diagnostic tool used in healthrelated training. Archives of Budo, 2012;8:179-90.
https://doi.org/10.12659/AOB.883491

13. Tamayo-Fonseca N, Nolasco A, Quesada JA, PereyraZamora P, Melchor I, Moncho J, et al. Self-rated health and hospital services use in the Spanish National Health System: a longitudinal study. BMC Health Services Research, 2015;15. https://doi.org/10.1186/s12913-015-1158-8.

14. Schnittker J, Bacak V. The increasing predictive validity of self-rated health. PLoS One. 2014; 9: e84933. https://doi.org/10.1371/journal.pone.0084933

15.Lobelo F, de Quevedo IG. The Evidence in Support of Physicians and Health Care Providers as Physical Activity Role Models. Am J Lifestyle Med. 2016; 10: 36-52. https://doi.org/10.1177/1559827613520120

16.Oberg EB, Frank E. Physicians' health practices strongly influence patient health practices. $J$ $R$ Coll Physicians Edinb. 2009; 39: 290-291. https://doi.org/10.4997/JRCPE.2009.422

17.Kalina RM, Kalina A. Methods for measurement of somatic health and survival abilities in the framework of the SPHSA questionnaire - methodological aspects. Arch Budo Sci Martial Art Extreme Sport, 2014; 9: 17-30.

18.Jagiełło W, Sawczyn S, Jagiełło M. The subjective profile of positive health and survival abilities in women differing as to physical activity. Arch Budo, 2012; 8: 219-224. https://doi.org/10.12659/AOB.883551

19.JagiełłoW, Sawczyn S, Jagiełło M, Michałowska-Sawczyn M. The subjective profile of positive health and survival abilities in female students differing as to physical activity. Teoriâ i Praktika Fizičeskoj Kul'tury, 2013; 5: 15-18.

20.Tsos A, Oliynyk OV, Szepeluk A. Subjective health profiles among Ukrainian students of medical vocational school. Health Problems of Civilization, 2016; 10(1): 32-38. https://doi.org/10.5114/hpc.2016.58206

21.Panjan A, Sarabon N. Review of Methods for the Evaluation of Human Body Balance. Sport Science Review, 2010; 19 (5-6): 131-163. https://doi.org/10.2478/v10237-011-0036-5

22. Osipov A, Guralev V, Kudryavtsev M, Kamoza T, Kuzmin V. Development of the ability to maintain body balance in dynamic conditions in beginning sambo wrestlers aged 11-12. Human Sport Medicine, 2018;18:88-94. https://doi.org/10.14529/hsm180413.

23.Osipov A, Kudryavtsev M, Iermakov S, et al. Development of the ability to maintain body balance in young athletes 1213 years practicing judo. Arch Budo Sci Martial Art Extreme Sport, 2018; 14.

24.Fabio RA, Towey GE. Cognitive and personality factors in the regular practice of martial arts. Journal of Sports Medicine and Physical Fitness. 2018;58(6):933-943. https://doi.org/10.23736/s0022-4707.17.07245-0 


\section{Information about the author:}

Dobosz D.; http://orcid.org/0000-0002-9919-6677; doboszdawid@interia.eu; Niepubliczny Zakład Opieki Zdrowotnej Ośrodek Rehabilitacji Marek Grodzki; Zgrzebnioka street 22, 43 - 110 Tychy, Poland.

Cite this article as:

Dobosz D. Empirical verification of self-rated positive health (somatic dimension) in women with professional competence in the field of health education. Pedagogics, psychology, medical-biological problems of physical training and sports, 2019;23(2):66-75.

https://doi.org/10.15561/18189172.2019.0203

The electronic version of this article is the complete one and can be found online at: https://www.sportpedagogy.org.ua/index.php/PPS/issue/archive

This is an Open Access article distributed under the terms of the Creative Commons Attribution License, which permits unrestricted use, distribution, and reproduction in any medium, provided the original work is properly cited (http://creativecommons.org/licenses/by/4.0/deed.en).

Received: 12.03.2019

Accepted: 10.04.2019; Published: 30.04.2019 